http://dx.doi.org/10.4314/bajopas.v12i1.33S

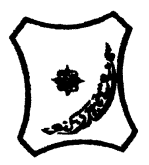

Bayero Journal of Pure and Applied Sciences, 12(1): 209 - 214

ISSN $2006-6996$

\title{
A SURVEY OF CO-INFECTION OF SOME PATHOGENIC BACTERIA WITH TB IN PATIENTS ATTENDING FEDERAL MEDICAL CENTER KATSINA, NIGERIA
}

\author{
${ }^{1}$ Abdulkadir, B., ${ }^{1}$ Abubakar, U., ${ }^{2}$ Abdullahi, B., ${ }^{3}$ Owuna, J. E., ${ }^{4}$ Murtala, R., ${ }^{1}$ Kabir, \\ K. and ${ }^{5}$ Ibrahim M. A. \\ ${ }^{1}$ Department of Microbiology Umaru Musa Yaradua University Katsina \\ ${ }^{2}$ Department of Microbiology Ahmadu Bello University Zaria \\ ${ }^{3}$ Department of Microbiology Nasarawa State University, Keffi Nasarawa \\ ${ }^{4}$ Department of Medical Laboratory Services Ahmad Sani Yariman Bakura Specialist Hospital Gusau \\ Zamfara \\ ${ }^{5}$ Department of Microbiology Kebbi State University of Science and Technology Alerio Kebbi State \\ *Corresponding Author: bashir.abdulkadir@umyu.edu.ng; \\ $(+2348065137374)$
}

\section{ABSTRACT}

Tuberculosis (TB) is known to be one of the oldest forms of human diseases which still remain the leading cause of death worldwide. It is characterized as a pulmonary disease which occurs due to accumulation of Mycobacterium tuberculosis (MTB) onto the lungs alveolar surfaces. M. tuberculosis is an implicated pathogenic bacteria associated with T.B. It is the chronic infectious disease caused by the tubercle bacillus (M. tuberculosis). This study was aimed to determine co-infection of other pathogenic bacteria within MTB patients attending Federal Medical Centre (FMC), Katsina. The study design was crosssectional, conducted to isolate some pathogenic bacteria that co-infected TB patients who are Acid fast bacilli (AFB) positive and AFB negative. The samples obtained were cultured on Blood, Chocolate and MacConkey agar and incubated at $37^{\circ} \mathrm{C}$ for 24 hours. Pure isolates were confirmed using Grams Staining and biochemical reaction. Data obtained were presented as simple percentage and using statistical analysis which revealed that the incidence was common among the age categories 51-60 with 28\%, followed by those $\geq 60$ years with $20 \%$. The lowest prevalence was recorded the at age category 11-20 with 10\%. Based on gender, males presented with the higher incidence (35/50) i.e. $70 \%$ than female (15/50) i.e. 30\%. Klebsiella pneumoniae, Staphyllococcus aureus and Pseudomonas aeruginosa were the most prevalent organisms isolated with $21.9 \%, 19.66 \%$ and $19.10 \%$ respectively. E. coli with $05.62 \%$ being had the least isolates. The research demonstrated the existence of both Gram positive and Gram negative bacterial pathogens that co-infect with TB patients, especially among the elderly males. Further research should be tailored towards investigating other pathogens that co-infect with MTB patients, such as fungi and viruses, in diversified hospitals in Katsina state and beyond.

Keywords: AFB, Pathogenic bacteria, Tuberculosis and Mycobacterium and Federal Medical Centre, Katsina.

\section{INTRODUCTION}

Tuberculosis (TB) is known to be one of the oldest forms of human diseases. Accordingly, it is known to cause mortality of nearly two million people each year (Pranita et al., 2016). In spite of the effective treatment strategies, the disease still remains the major cause of death among the different curable infectious diseases (Kavita et al., 2016). TB could affect different places e.g. bones, the nervous system or many other organ systems, but basically, it is characterized as a pulmonary disease which occurs due to accumulation of Mycobacterium tuberculosis (MTB) onto the lungs alveolar surfaces. $M$. tuberculosis is a constrained pathogenic bacterial species which belong to the family of mycrobacteriaceae. It was first discovered by Robert Koch in 1882 (Christina et al., 2016). It can form acid stable complexes made up of peptidoglycan during Gram staining. It mainly infects the lungs of humans. There are many methods to diagnose tuberculosis, among which are tuberculin skin tests, acid-fast stain, and chest radiographs (Kaiming, 2016). 
M. tuberculosis has developed resistance over time against the drugs used for its treatment hence drug resistance has become a serious problem around the world. The effective treatment regime for TB must contain multiple drugs to which the organism is susceptible to. This is because using a single particular drug for its treatment may lead to the development of drug resistant bacterial populations. Using two or more drugs simultaneously will help each other in order to counter the problem of resistance synergy towards a particular drug. During the initial stages of $T B$, it is difficult to select the particular drug to which the patients' isolates would be susceptible. This selection criterion is important because improperly selected drug would subsequently lead to the development of additional drug resistant organisms. The antibiotics commonly used for TB treatment include isoniazid (INH), rifampicin (RIF), pyrazinamide (PZA), and ethambutol (EMB) or streptomycin (SM). The course of the drug therapy normally last for at least 6-9 months. It is important to take the medication as per the guidance of the Physician and adherence to the full course of the medication (Shams et al., 2014).

Co-Infection of tuberculosis with other bacteria has not been widely reported. Although suppressed bacterial infections can occur in TB patients, the simultaneous occurrence of both infections leads to delayed diagnosis and inadequate treatment. Tubercular bacterial coinfection needs to be considered, especially if TB occurs in atypical pulmonary or extrapulmonary locations. Tubercular and bacterial co-infection is uncommon in patients with intact immunity, but has been described in immunodeficient hosts such as those with HIV-AIDS. There are a few reports about the co-occurrence of TB with organisms like Mycobacterium leprae, $M$. intacellulare, Streptococcus pneumonia, Salmonella typhi, Streptococcus milleri, Psedumonas species and Klebsiella species (Arora et al., 2015).

Tuberculosis patients are found to have coinfection with HIV, likewise tuberculosis patients are suspected to have co-infection with fungi (Candida spp.) and viral infection like HIV is normally believed to be the predisposing agent of tuberculosis, because of the suppression of immunity that it brings about. Candida infections also normally manifest after immunosuppression, and are normal consequences of TB infections (Ndukwu, 2016). Therefore, the aim of this work is to look at the possible pathogenic bacteria co-infecting with MTB patients in the study area.

\section{MATERIALS AND METHODS \\ Sample Population/Size}

A prevalence rate of $17.3 \%$ from a previous study in Kebbi state by Abdulkadir and Ibrahim (2018) was used to determine the sample size (220 samples), using an equation described by Naing et al., (2006). A total of fifty (50) samples were used during the research in order to minimize error.

\section{Collection and Transport of Sputum}

Sputum for microbiological investigation is collected and transported as follows. Clean dry, wide-necked, leak-proof container, was given to the patient and requested him or her to cough deeply to expectorate and produce a sputum specimen. The sample was immediately transported to the Microbiology Laboratory in the Federal Medical Center for processing.

\section{Inclusion criteria}

This study included all those patients that present to be AFB positive and AFB negative.

Also it included patients from the age range 11 $\geq 60$.

\section{Exclusion criteria}

This study does not include patients below age 11 category.

It also does not involve patients presented with other infection like HIV/AIDS patient.

\section{Ethical Approval and Clearance}

Ethical approval for the study was obtained from the office of medical director Federal Medical Center Katsina State, with the HREC assigned number (FMCNHREC. REG. NO. 3/082012), before the commencement of the study.

\section{Acid Fast Stain}

A smear was made on a clean glass slide, and was then allowed to air dried and then fixed in alcohol. To raise the smear, it was then covered with carbon fuchin stain and heated until vapour just begins, the stain was washed off with clean water and then covered with $3 \% \mathrm{v} / \mathrm{v}$ acid alcohol for five minutes it's then washed well with clean water and covered with malachite green stain for two minute then washed with clean water. The prepared smeared was then drained using draining rack to air dried. The slide was examined under X100 (oil immersion) objective lense (Sagar, 2015).

\section{Culturing and isolation}

Specimens were inoculated onto prepared MacConkey Blood agar and Chocolate agar were inoculated and incubated at $37^{\circ} \mathrm{C}$ for 24 hours. 
The discrete colonies formed were used in obtaining the pure isolates, by sub-culturing the colonies in a purely prepared MacConkey Blood agar and Chocolate agar for microbial characterization.

\section{Morphological characterization}

The colonies of the isolates were examined and recorded based on their colonies colour, size, margin, edge, consistency, opacity and colour change in the medium at the end of 24hours.

\section{Gram staining}

Bacterial smears of 24 hrs old cultures were made on clean glass slides, heat fixed and stained as follows: The slide was flooded with crystal violet solution (primary stain) for one minute, drained and rinsed with water; followed by Grams iodine solution for one minute, drained and rinsed with water. Decolourised with ethyl alcohol for 30 Seconds and later counterstained with safranin for one minute and observed under an oil immersion microscope (Michael and Burton, 2010).

\section{Biochemical Test}

Indole test

The cultured media was inoculated into tryptone broth and incubated at $37^{\circ} \mathrm{C}$ for 24 hours. About $0.2 \mathrm{ml}$ of Kovac's reagent was then added to the test tube, shaken and allowed to stand. The formation of red ring on the surface of the broth confirmed the production of indole (Michael and Burton, 2010).

\section{Methyl red test}

The cultured media was inoculated with Methyl red - Vogues Proskauer (MR-VP) broth and incubated for 24 hours at $370 \mathrm{C}$. The appearance of a red colour on addition of methyl red solution was considered as positive (Michael and Burton, 2010).

\section{Voges - Proskauer test}

Cultured was inoculated with MR-VP (glucose broth) medium and incubated at $37^{\circ} \mathrm{C}$ for 24 hours. After incubation, $3 \mathrm{ml}$ of Barrit's reagent A (5\% alpha naphthol: $5.0 \mathrm{~g}$ Absolute ethanol: $95 \mathrm{ml}$ ) and one $\mathrm{ml}$ of Barrit's reagent $B$ (Potassium hydroxide: $40 \mathrm{~g}$; Creatine: $3 \mathrm{~g}$; Distilled Water: $1000 \mathrm{ml}$ ) were added. The tubes were shaken and allowed to stand for 15 minutes and observed for colour change. The development of pink colour was considered as positive (Michael and Burton, 2010).

\section{Citrate Utilization test}

The test isolates were streaked over the slant of Simmon's citrate agar and incubated for 24hrs at $370 \mathrm{C}$. Growth on the slant and change in colour to blue of the medium indicates positive result (citrate is been utilized by the organism) (Michael and Burton, 2010).

\section{Catalase Test}

A drop of hydrogen peroxide was put at the center of glass slide and the colony of 24 hour cultured media was picked and smeared. The formation of bubbles within 3-4 seconds was recorded as positive (Michael and Burton, 2010).

Coagulase Test

A $0.1 \mathrm{ml}$ of the plasma was dropped at the center of the slide and the colony of 24 hour cultured media was picked and smeared. Agglutination is formed within 1 minute which was recorded as positive result (Michael and Burton, 2010).

\section{Oxidase test}

A piece of filter paper was soaked with a few drops of oxidase reagent. A colony of the test organism was then smeared on the fiter paper. A deep purple colour on the smeared portion indicates the presence of cytochrome enzyme oxidase (Michael and Burton, 2010).

\section{Statistical analysis}

Data was presented using descriptive statistics and analyzed using statistical tool; GraphpadInstat statistical software version 3.0.

\section{RESULTS}

From Table 1 the study revealed the incidence of TB which occurs mostly within the age range of 51 - 60 with $28 \%$, followed by $\geq 61$ with $20 \%$, $31-40$ with $16 \%, 21-30$ with $14 \%, 41 \% 41-50$ with $12 \%$, the lowest prevalence was observed in the 11-20 age category with $10 \%$ only. Statistically there is no significant difference between age group category with $x^{2}=(3.358)$, $\mathrm{df}=(5)$ and $p$-value (0.6449).

Result shows that, 35 were males and 15 were females $23(46 \%)$ males were TB positive while $12(24 \%)$ were males TB negative also $6(12 \%)$ were females and TB positive while $9(18 \%)$ were females and TB negative. Statistically, there is no significant difference with $x^{2}$ (1.892), df (1) and p-value (0.1689). 
Table 1. Occurrence of TB based on age

\begin{tabular}{|c|c|c|c|}
\hline Age group & $\begin{array}{l}\text { No. of patients } \\
\text { examined }\end{array}$ & $\begin{array}{l}\text { No. of patie } \\
\text { pathogens } \\
\text { Positive }\end{array}$ & $\begin{array}{l}\text { nts with } \\
\text { negative }\end{array}$ \\
\hline $11-20$ & 5 & $\begin{array}{l}02(6.90 \%) \\
(14.29 \%)\end{array}$ & 03 \\
\hline $21-30$ & 8 & $\begin{array}{l}03(10.34 \%) \\
(19.05 \%)\end{array}$ & 04 \\
\hline $31-40$ & 8 & $\begin{array}{l}04(13.80 \%) \\
(19.05 \%)\end{array}$ & 04 \\
\hline $41-50$ & 6 & $\begin{array}{l}05(17.23 \%) \\
(04.76 \%)\end{array}$ & 01 \\
\hline $51-60$ & 14 & $\begin{array}{l}09(31.03 \%) \\
(23.80 \%)\end{array}$ & 05 \\
\hline$\geq 61$ & 10 & $\begin{array}{l}06(20.69 \%) \\
(19.05 \%)\end{array}$ & 04 \\
\hline Total & 50 & $\begin{array}{l}29(100 \%) \\
(100 \%)\end{array}$ & 21 \\
\hline
\end{tabular}

Table 2. Occurrence of TB based on Gender

\begin{tabular}{llll}
\hline Gender & No. of patients examined & \multicolumn{2}{l}{ No. of patients with pathogens } \\
& & positive & negative \\
\hline Males & 35 & $23(46 \%)$ & $12(24 \%)$ \\
Females & 15 & $06(12 \%)$ & $09(18 \%)$ \\
\hline
\end{tabular}

A total of 178 isolates were obtained from both TB negative $85(47.75 \%)$ and positive 93 $(52.25 \%)$ patients. Hence more bacteria are found from TB positive than from TB negative with $K$. pneumoniae been the most commonly isolated organisms than any other bacterium, while $S$. pneumoniae and $E$. coli are the least.

Table 3: Bacterial pathogens isolated from the patients

\begin{tabular}{llcll}
\hline Pathogens isolated & $\begin{array}{c}\text { No. of isolates } \\
\text { Pegative }\end{array}$ & Total & Occurrence (\%) \\
\hline K. pneumonia & 21 & 18 & 39 & $21.9 \%$ \\
S. aureus & 18 & 17 & 35 & $19.66 \%$ \\
P. aeruginosa & 13 & 17 & 34 & $19.10 \%$ \\
H. influenza & 13 & 13 & 26 & $14.61 \%$ \\
M. catarrhalis & 09 & 04 & 13 & $07.30 \%$ \\
S. pneumonia & 07 & 14 & 21 & $11.80 \%$ \\
E. coli & 08 & 02 & 10 & $05.62 \%$ \\
Total & $\mathbf{9 3}$ & $\mathbf{8 5}$ & $\mathbf{1 7 8}$ & $\mathbf{1 0 0 . 0 0 \%}$ \\
\hline
\end{tabular}

\section{DISCUSSION}

In this study, 35 male patients (70\%) and 15 in female patients (30\%) present with co-infection. This finding was closely related with the previous study reported by Amaryllis et al., (2016) with slight difference in the number of male patients. Out of the 50 samples screened, all the samples were significant with the target organism that is $100 \%$. Among the organism isolated are two Gram positive bacteria ( $S$. aureus and $S$. pneumoniae) and the rest are Gram negative ( $K$. pneumoniae, $P$. aeruginosa, H. influenza, M. cattarrhallis and E. coli). This occurrence is higher the than previous studies in
Kano, Nigeria Taura et al., (2013) and in Benin City Egbe et al., (2011). The bacterial pathogens isolated are similar to that of the work of Vijay and Dalela (2016) in Jhalawar, India.

In this research $K$. pneumoniae was found to be the most predominant pathogen isolated from the sample, this is in agreement with the previous studies conducted by Egbagbe and Mordi (2006); Egbe et al., (2011); Vijay and Dalela (2016). However, the study of Taura et al., (2013) reported S. pneumoniae as the most predominant pathogen followed by $K$. pneumoniae. 
Also, the study of Egbagbe and Mordi (2006) reported the absence of $S$. aureus as the second most leading pathogen. Furthermore, based on gender screened during the study, we found male $(70 \%)$ recorded high percentage than female $(30 \%)$ in our research which is similar to the previous study conducted by Taura et al., (2013) and Vijay and Dalela (2016).

The prevalence based on age group category showed that those in the age range 51-60 and $\geq$ 60 are the most susceptible co-infection. It also agreed with the findings of Panda et al., (2012), where they recorded a higher occurrence among patients ranging from $51-60$ and $60-70$ years. Millet (2013) working with older adults in the United Kingdom also recorded an increase in prevalence of lower respiratory tract infections with increase in age. A diminishing immunity due to age as well as other health complications is probable reasons for this trend Egbe et al., (2011) as recorded in previous study.

\section{CONCLUSION}

This research demonstrated the existence of numerous Gram negative and Gram positive

\section{REFERENCES}

Abdulkadir, B. and Ibrahim, M. A. (2018). Confirmation of Symptomatic Tuberculosis using Gene Xpert (MTB/RIF) among Patients within Zuru Emirate Council Kebbi State, Nigeria. UMYU Journal of Microbiology Research, 3 (2), 32-38.

Amaryllis, L., Nabajit, D., Hafizur, R., and Devjyoti, K. (2016). A Study on Bacterial Pathogens causing Secondary Infections in Patients Suffering from Tuberculosis and their Pattern of Antibiotic Sensitivity. International Journal of Current Microbiology and Applied Sciences ISSN: 2319-7706: 5(8): 197203.

Arora, A. A., Krishnaswamy, U. M., Moideen, R. P. And Padmaja, M. S. (2015). Tubercular and bacterial coinfection: $A$ case series. Lung India; 32:172-4.

Christina, S. H. et al. (2016). Mycobacterium tuberculosis Induces Expansion of Foxp3 Positive CD4 T-cells with a Regulatory Profile in Tuberculin Non-sensitized Healthy Subjects: Implications for Effective Immunization against TB. Journal of Clinical Cell Immunology, 7: 428.

Egbagbe, E. E. and Mordi, R. M. (2006). Aetiology of Lower Respiratory Tract Infection inBenin City, Nigeria. Journal organisms co-infection among TB positive and negative patients. In the study, the incidence was observed among elderly patients than younger ones. Males demonstrated higher coinfection with the pathogenic microbes than the females. Furthermore, $K$. pneumoniae and $S$. aureus are the most predominant organisms isolated with $E$. coli being the least prevalent.

\section{RECOMMENDATIONS}

1. This study restricts itself to pathogenic bacteria that co-infected TB patients, thus the need emanates for the conductance of further studies on other aetiological agents, such as fungi and viruses.

2. Future effort should be tailored towards other areas and health centres in Katsina State and Nigeria at large.

3. Hospital should be encourage to incorporate identification of aetiological agent of T.B and the presence of other pathogens so as to avoid the failure of therapy. This will help in tackling the danger of co-infection as seen this survey.

of Medicine and Biomedical Research, 5(2):22-27.

Egbe, C. A., Ndiokwere, C. and Omoregie, R. (2011). Microbiology of Lower Respiratory Tract Infections in Benin City, Nigeria. Malaysian Journal of Medical Science, 18(2):27-31.

Kaiming, L. (2016). Genetic Diversity and Drug Resistance of 133 Mycobacterium tuberculosis Isolates from Jiangxi Province, China. MBL.

Kavita, G. et al. (2016). Changing Trends in the Susceptibility Pattern of Mycobacterium tuberculosis Over a Decade from a Tertiary Care DOTS Centre Delhi. Mycobact Dis, 6: 211.

Micheal, J., Beboffe and Burton, E. Pierce. (2010). A Photographic Atlas Microbiology Laboratory. Fourth Edition.

Millett, E. R. C., Quint, J. K., Smeeth, L., Rhian, M., Daniel, Thomas, S. L. (2013). Incidence of community-acquired lower respiratory tract infections and pneumonia among older adults in the United Kingdom: A population-based study. PLoS One.8(9):e75131.

Monica Cheesbrough (2006). District Laboratory Practice in Tropical Countries. 2nd Edition, Cambridge University Press: 6470. 
Ndukwu, C. B, C.Mbakwem-Aniebo, N.FrankPeterside (2016). Prevalence of Candida Co-Infections among Patients with Pulmonary Tuberculosis in Emuoha, Rivers State, Nigeria. Journal of Pharmacy and Biological Sciences. 11(5) (Available @www.iosrjournals.org).

Parameswaran, S. and Sanjukta P. (2016) Rv3802c in Tuberculosis Therapeutics. Mycobacterial Disease: 6: 204.

Pranita, W. et al. (2016). Excretory Secretory Proteins Released during Growth of Mycobacterium tuberculosis (H37Ra), With Diagnostic Potential in Pulmonary and Extra Pulmonary Tuberculosis. Mycobacterium Disease. 6: 215.

Sagar, A. (2017). Habitat and Morphology of Klebsiella pneumonia [online]. Available @https://mirobenotes.com/habitat-andmorphology of Klebsiella pneumonia.

Sulaiman, S. et al. (2014). Prevalence of Tuberculosis in District KharBajaur Agency, Khyber Pakhtunkhwa Pakistan. Biochem Anal Biochem; 3:148.

Taura, D. W., Hassan, A., Yayo, A. M. and Takalmawa, H. (2013). Bacterial isolates of the respiratory tract infection and their current sensitivity pattern among patients attending Aminu Kano Teaching Hospital Kano-Nigeria. International Research Journal of Microbiology, 4(9):226-231.

Vijay, S. and Dalela, G. (2016). Prevalence of LRTI in Patients Presenting with Productive Cough and Their Antibiotic Resistance Pattern. Journal of Clinical and Diagnostic Research, 10(1):9-12. 